\title{
RIGHT VENTRICULAR STENOSIS (BERNHEIM'S SYNDROME)
}

\author{
BY \\ TERENCE EAST AND CURTIS BAIN \\ From the Cardiological Departments of King's College Hospital and Harrogate General Hospital
}

Received December 2, 1948

Since this clinical state was first described by Bernheim in 1910, very little has appeared in the English language or in journals easily accessible in this country; or at all in recent years. The recent paper on the subject by Russell and Zohman (1945) gives references many of which we cannot check. A good deal was written in 1930 and 1931, and there were seven papers associated with the name of Mazzei and five with that of Martini. We record these cases to draw attention to a pathological state that appears to explain satisfactorily certain rather curious clinical phenomena.

The essential feature of the syndrome is what appears to be a clinical paradox. There are conspicuous features of apparent failure of the right side of the heart in a patient with a lesion affecting the left side. The explanation for this was offered by Bernheim (1910), who pointed out that the septum of the ventricles bulged into the cavity of the right ventricle, and so prevented it filling. Podestà (1936) has called it dextroventricular stenosis. The progress of the disorder has been divided into two stages by Mazzei (1931). In the first the infundibulum becomes dilated and so allows the flow of blood to be maintained despite the interference with the filling of the ventricle. We have satisfied ourselves by means of casts taken of the cavity of the upper part of the right ventricle in two cases that this is so. In the second phase this adjustment becomes inadequate and the signs of hepatic and jugular engorgement are seen. The pulmonary circulation remains unaffected until near the end, when a final congestion of the lungs may appear.

\section{CASE RePorts}

The clinical and post-mortem findings of our five cases now follow and will be discussed and compared with others reported.

Case 1. A labourer, aged 32, was admitted to hospital in January 1945, complaining of swelling of the legs and feet and of fatigue, but had no shortness of breath. As a child he had attended hospital on account of his heart, and had not been allowed to play games at school. Since leaving school, however, he had been well and had lived an unrestricted life.

The patient was a fat, well-built man. There was no cyanosis. The veins in the neck were not obviously engorged, but the liver was enlarged about one and a half inches below the edge of the ribs. The backs of the legs and the buttocks were swollen. His aspect generally was somewhat pale.

The cardiac dullness extended three-quarters of an inch to the right of the sternum. The apex beat was forcible and situated five and a half inches to the left of the midline in the sixth left interspace. A very loud harsh systolic murmur was best heard three inches from the midline in the fifth left interspace. This murmur was accompanied by a thrill. The murmur was conducted to the mitral and pulmonary areas and to the left axilla, but not particularly upwards. The heart sounds at the apex were quite loud, while those at the base were faint; the pulmonary second sound was louder than the aortic. The pulse was regular, of poor volume, and not anacrotic, with a blood pressure of $100 / 80$. Screening of the heart showed that the right auricle was obviously engorged, the left ventricle was not conspicuously enlarged, and the pulmonary vessels were somewhat prominent. The aorta was normal (Fig. 1).

Barium in the œsophagus showed slight engorgement of the left auricle. The cardiogram showed no axis deviation; the rhythm was normal but the effect of digitalis was apparent in R-T negativity in all three leads (Fig. 2). The diagnosis appeared to have lain between pulmonary stenosis, aortic stenosis, and patent interventricular septum. The site of the murmur, the predominance of right ventricular failure, the absence of an anacrotic pulse 
and the freedom from dyspnœa, also the equivocal cardiogram, made one decide upon the last, particularly in view of the presence of the lesion in childhood.

At first, treatment for the congestive heart failure was successful. Mercurial diuretics were given freely and he was able to go to a convalescent home. After a month or two he returned with further development of failure. In spite of treatment the anasarca gradually returned and steadily increased. He was never orthopnoic and could lie fairly flat in bed. A pulmonary infarct occurred, and he slowly deteriorated and died.

Autopsy. There was gross anasarca; profuse ascites, and a moderate hydrothorax on both sides. There was no pulmonary odema and the lungs were not grossly engorged: their dryness was remarked on at the time. The heart was very large $-720 \mathrm{~g}$. The left ventricle showed gross hypertrophy, the septum being very thick and bulging extensively into the right ventricle. This was considerably dilated, particularly in the infundibulum. The aortic valves were stenosed as a result of congenital fusion and subsequent calcification. The appearance was that of a bicuspid valve. Calcification was extensive, and in the depths of the anterior cusp there seemed to be traces of a small raphe. The interventricular septum was not patent. The coronary sinus was greatly dilated, perhaps by the high pressure in the right auricle. There was gross passive engorgement of the liver.

Comments. The diagnosis was missed in this case because of the site of the murmur and the absence of confirmatory signs of aortic stenosis. 
The freedom from embarrassment of the pulmonary circulation, the absence of left axis deviation in the electrocardiogram, and the conspicuous predominance from the first of the results of right side failure made the diagnosis in favour of a patent interventricular septum (Maladie de Roger); for pulmonary stenosis did not appear to be in any way indicated.

Reflection on the findings at autopsy suggested that the clinical manifestations indicated Bernheim's syndrome. The stenosis of the aortic valves should have sooner or later led to failure of the left ven- be to interpret obvious physical signs, and on reflection it is difficult to see what might have led one to suppose that aortic stenosis was really the cause of the murmur and thrill. Failure of the right ventricle would have been expected to develop early had the ventricular septum been patent.

Case 2. A woman, aged 62, became more and more out of breath on exertion. This symptom was first noted on hills and long walks, and later on climbing stairs. For the last six months she had been breathless on any slight activity. During the

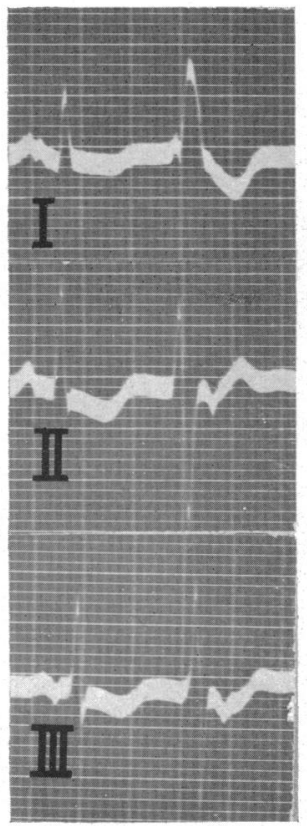

FIG. 2.

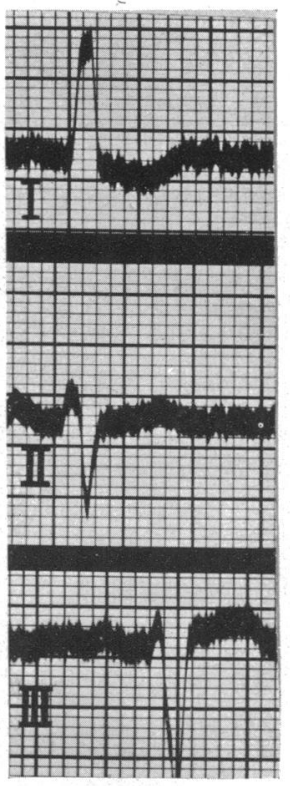

FIG. 3.

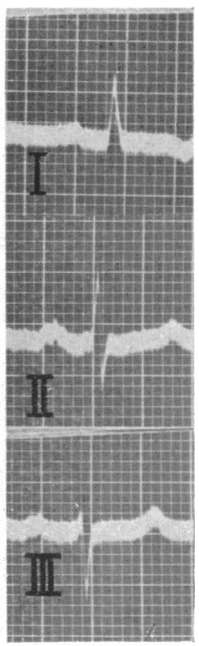

Fig. 4.

FIG. 2.-Case 1. Standard three leads, showing bigeminy and negative $\mathrm{T}$ waves, but no left axis deviation.

FIG. 3.-Case 2. Standard three leads, showing left axis deviation.

Fig. 4.-Case 4. Standard three leads, showing left axis deviation.

tricle, but right ventricular failure was predominant from the first. On Bernheim's theory the encroachment on the cavity of the right ventricle would have been responsible for the early state of the failure of the right side. The absence of engorgement and œdema of the lungs post-mortem was very striking. The absence of left axis deviation agrees with some cases regarded as examples of Bernheim's syndrome, but it seems likely that unipolar limb leads would have shown that the heart was vertical, and consequently the axis deviation due to left ventricular hypertrophy was lacking.

The incorrect diagnosis shows how hard it may winter before coming into hospital she had been confined to bed for two months; there had been several attacks of bronchitis. She was now rather breathless at rest. There was slight swelling of the ankles, but the liver and the external jugular veins were not engorged. The heart rate was 100 , with the rhythm regular. The pulse showed alternation and the wave was slightly anacrotic. The blood pressure was 220-210/145. There was thickening of the brachial and retinal arteries. The apex beat was weak and diffuse, extending five inches to the left of the midline, in the fifth intercostal space. In the mitral area a presystolic gallop rhythm was audible. 
At the base, in the aortic area a rough systolic murmur could be heard, extending into the arteries of the neck. No thrill was palpable. The aortic second sound was faint; at the bases of the lungs were fine scattered crepitations; the skiagram showed that the pulmonary veins were engorged. The cardiogram (Fig. 3) showed evidence of left ventricular hypertrophy. The diagnosis was failure of the left ventricle due to hypertension and slight aortic stenosis. Failure of the right ventricle was to 22 from 30 a minute. On the evening of the third day she died suddenly.

Autopsy. There was gross œdema and venous congestion. The liver was " nutmeg," weighing $1615 \mathrm{~g}$. The spleen showed severe chronic congestion. The heart weighed $600 \mathrm{~g}$. The left ventricle was enormously hypertrophied, the wall being about $30 \mathrm{~mm}$. thick (Fig. 5). The septum, which was $20 \mathrm{~mm}$. thick, bulged into the cavity of the right ventricle. The aortic valve was stenosed, the cusps

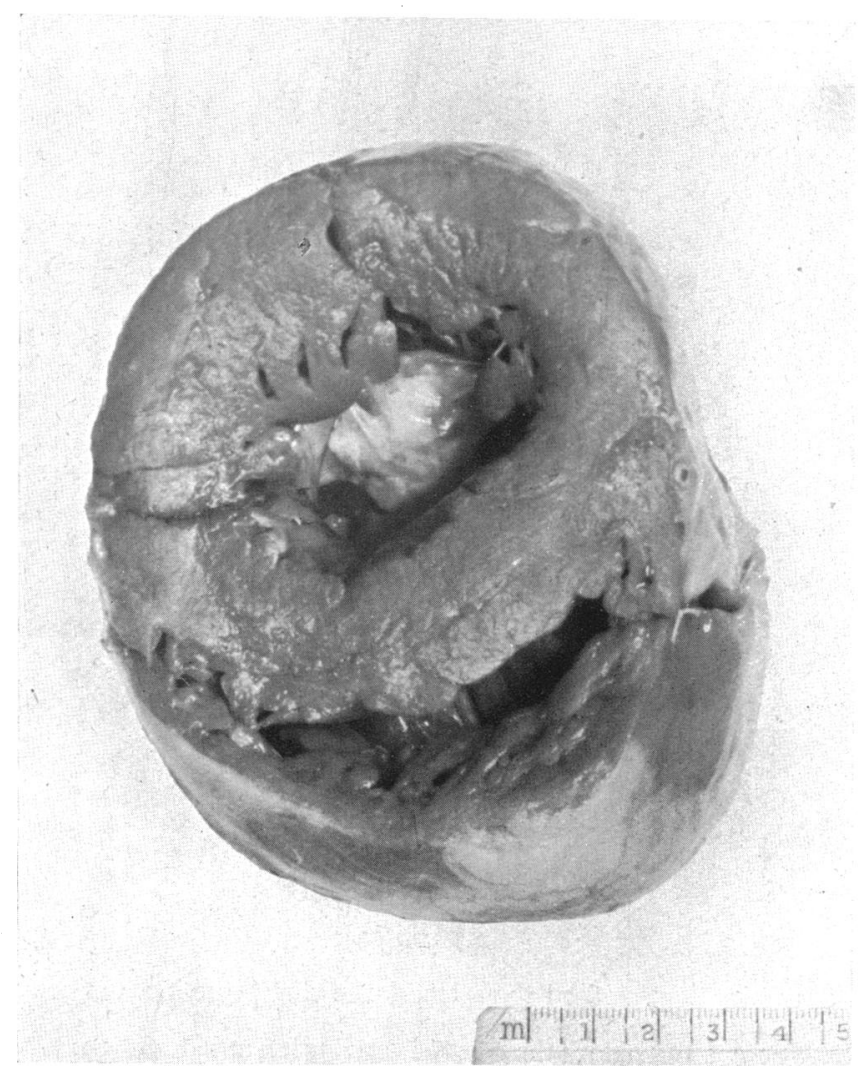

FIG. 5.-Case 2. Transverse section of ventricles looking towards the base. The thickened septum bulges into the right ventricle.

developing. Under treatment she improved and kept fairly well on leaving hospital until six months later, when there was a further attack of bronchitis. This time there was rapid development of œdema and venous congestion. The liver was three inches below the ribs, and there was anasarca to the waist. The jugular veins were prominent half way up the neck. She was rather blue, but not orthopnœic, and could lie fairly flat. A few crepitations were heard in the lungs; the pulmonary second sound was loud. After three days in hospital the respiratory rate fell being fused and calcified. A slight ridge below the free margin suggested a rheumatic infection in the past. The lungs, in contrast to the liver, were free from engorgement, and showed hardly any œdema; the right weighed $550 \mathrm{~g}$. (normal $500 \mathrm{~g}$.), and the left 380 g. (normal 420 g.). Microscopical section showed some engorgement and scattered heart failure cells only. There was but a trace of fluid in the left pleural sac. There was nothing to explain the sudden death except the aortic stenosis.

Comments. This patient, developed gradual 
failure of the left ventricle about two years before her death. Edema of the ankles did not appear until the last six months. The final failure appears to have been precipitated by an attack of bronchitis and was marked by severe venous congestion, which increased rapidly in the last three weeks. Although she was breathless on admission to hospital, this was soon relieved. The important point is the freedom of the lungs from cedema and engorgement post-mortem. It would appear likely that the bulging of the septum into the right ventricle prevented the lungs from being overfilled, although the aortic stenosis and hypertension affecting the left ventricle would have made this a likely finding. It is true that it is common to find failure of the right ventricle following that of the left in such cases as these, and this has always been regarded as a true " back pressure" phenomenon. In this instance it would seem more probable that the cause was different; otherwise the lung would have shown the usual intense engorgement associated with a failing left ventricle. The course of the illness suggests that in the earlier phases the lungs may have been involved but that the development of the stenosis of the right ventricle relieved them.

Case 3. A woman, aged 63, had complained of dyspnœa, gradually increasing in intensity, for the previous four years. During the last six months she had had acute attacks of breathlessness at night and had often been orthopnœic. In the last month the legs had become odematous, and since then she had been confined to bed. Auricular fibrillation was present, with a heart rate of 70 , for she had been taking Guy's pill twice a day for two years. The heart was greatly enlarged to the left, with a heaving apex beat. A rough systolic murmur was heard at the apex. The pulmonary second sound was abnormally loud. Crepitations were heard at the bases of both lungs. OEdema was present halfway up the thighs, and there was a small sacral pad. Ascites was present, and the liver was enlarged two inches below the ribs. The cervical veins were engorged.

A cardiogram showed auricular fibrillation. The limb leads indicated right axis deviation, but the præcordial leads confirmed the clinical evidence of left ventricular hypertrophy.

It was supposed that she had previously had high blood pressure and was now in the later stages of congestive failure with auricular fibrillation. She refused to. come into hospital and deteriorated steadily at home; but after a month she had to be admitted. There was now massive œdema of the legs and abdominal wall, and even the hands were somewhat swollen. There were no signs in the lungs and the breathing was easy; she was able to lie quite flat without discomfort.

The cardiogram now showed advanced right axis deviation, with a vertical heart, but the chest leads still indicated hypertrophy of the left ventricle
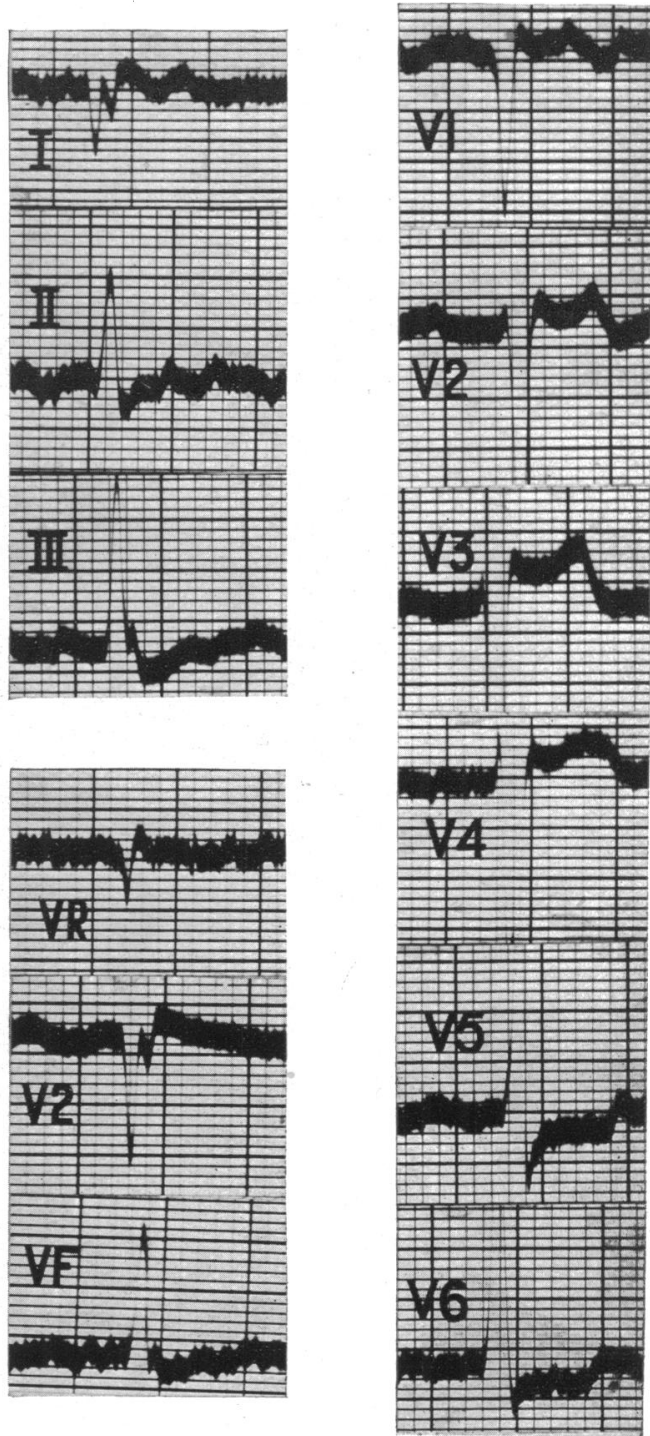

FIG. 6.-Case 3. Standard leads show right axis deviation. Unipolar limb leads show a vertical heart. Unipolar chest leads show hypertrophy of the left ventricle.

(Fig. 6). She slowly got worse, and she died a month later.

The clinical diagnosis of Bernheim's syndrome was suggested on the finding of gross congestive failure in a case of predominantly left-sided disease 
together with freedom from embarrassment of the pulmonary circulation. The findings at autopsy confirmed this diagnosis.

Autopsy. Edema was present in the lower parts of the body. There was no free fluid present in the pleural sacs; the lungs were well ærated throughout and free from odema. Venous congestion was not conspicuous. The weight of the right lung was $420 \mathrm{~g}$. (normal $500 \mathrm{~g}$.), and of the left lung $390 \mathrm{~g}$. (normal 425 g.).

Section of the lungs showed no evidence of chronic venous congestion. On the whole congestive changes were mild. An early bronchopneumonia was developing in the right lower lobe, and here there appeared œdema in the alveoli and congestion of capillaries. myocardium showed a generalized increase in fibrous tissue which was evenly scattered between the muscle fibres. These fibres themselves showed no degeneration but were definitely hypertrophied. The liver was enlarged (1480 g.) and showed evidence of venous congestion. The kidneys were slightly contracted and granular. There was much free fluid present in the abdomen.

Comments. The conspicuous finding was hypertrophy of the myocardium of the left ventricle, with great increase in thickness of the interventricular septum, which encroached upon the cavity of the right ventricle. The conspicuous venous engorgement of the portal system was in striking contrast with the absence of engorgement in the pulmonary circulation.

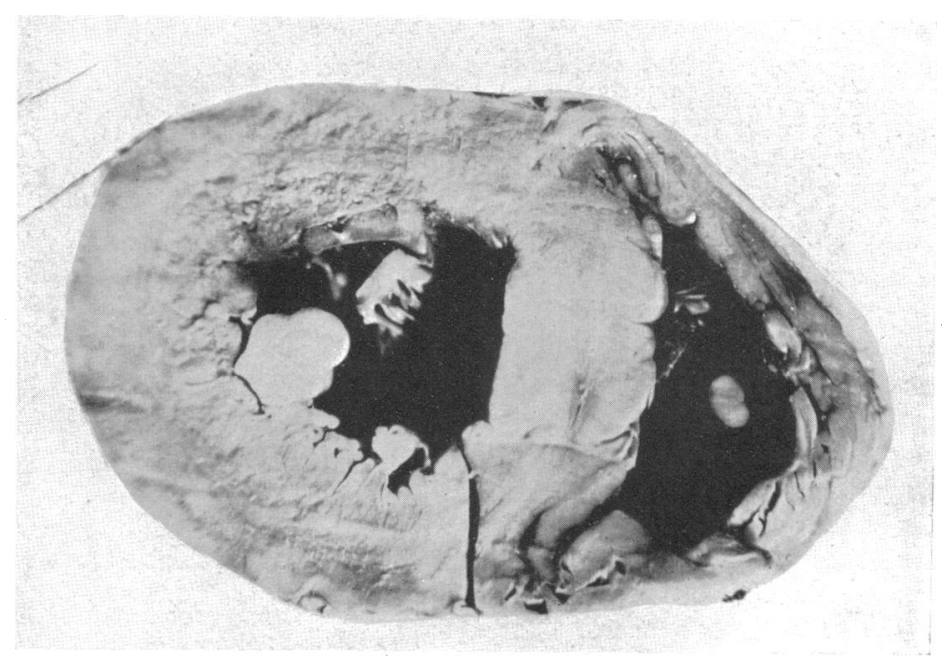

FIG. 7.- Case 3. Transverse section of the ventricles, looking towards the base. The thickened septum bulges into the right ventricle.

The heart was greatly enlarged, weighing $810 \mathrm{~g}$. The most striking feature was the concentric hypertrophy of the muscle of the left ventricle. The wall of the right ventricle was also hypertrophied, and the thickness of the interventricular septum was much increased. The thickness of the right ventricle about halfway up was 4 to $5 \mathrm{~mm}$., and that of the left ventricle about the same level was $20 \mathrm{~mm}$. The septum was 20 to $24 \mathrm{~mm}$. in thickness throughout. The cavity of the right ventricle was encroached upon by the bulge of the thickened interventricular septum into it (Fig. 7). There was no apparent dilatation of this chamber. The internal capacity was therefore very considerably diminished. The right auricle was dilated. All valves were normal. There were also numerous areas of atheromatous degeneration in the coronary arteries. The
On these findings the clinical diagnosis of Bernheim's syndrome would appear to be confirmed.

Case 4. A woman, aged 54, first came under observation in 1932 when she attended hospital for a mild toxic goitre. This was removed and she made a good recovery.

In 1938, when she was 47 , she again attended hospital. She had had several severe paroxysms of auricular fibrillation. There had been a swelling of the ankles and pain over the front of the chest. The signs in the heart now showed aortic stenosis.

In 1945 , when she was 54 , she was again admitted to hospital. During the past seven years she had had attacks of fibrillation from time to time, and in the last year or two she had had a good deal of pain under the sternum on walking. Breathlessness had 
not been a conspicuous symptom; there never had been any orthopnœa. There was a good deal of swelling of the ankles and a considerable pad in the sacral area. The veins in the neck were considerably engorged and filled from below up to about four. inches above the level of the right auricle when she was sitting nearly upright. The liver was a good deal enlarged. The apex beat reached the sixth space five inches from the midline. There was a typical murmur of aortic stenosis. The aortic second sound was not audible. Auricular fibrillation came and went. There was, however, no sattisfactory improvement in the signs of congestive heart failure; digitalis and diuretics were ineffective: gradually the œdema became more general and her condition deteriorated. She was never. in any way breathless and she gradually sank and died. The electrocardiogram had shown auricular fibrillation, with left axis deviation.

It was noticeable that this patient, who had evidently had aortic stenosis for a good many years, never complained of shortness of breath. The final phase of heart failure lasted two months and was marked by symptoms of failure of the right ventricle, whereas one would have expected a phase of left ventricular failure.

Autopsy. There was generalized anasarca; a few ounces of fluid were present in each pleural sac but the lungs were remarkably dry, but little engorged and quite free from odema. The right weighed $510 \mathrm{~g}$. (normal $500 \mathrm{~g}$.) and the left $390 \mathrm{~g}$. (normal $425 \mathrm{~g}$.). The heart weighed $540 \mathrm{~g}$. There was much engorgement of the right auricle and of the great veins. The right ventricle was full; the left ventricle was greatly hypertrophied; and the septum was very thick and bulged prominently into the cavity of the right ventricle. The tricuspid ring was slightly enlarged. The aortic valves were fused, so that a small slit-like opening only was left. The valves were heavily calcified and a ridge of nodular calcium deposit seemed to mark a raphe where the commissure of the two anterior cusps might have been. These were probably congenital bicuspid aortic valves which had become calcified. The stenosis had presumably developed progressively in the course of the last fourteen years.

Comments. In this case it is notable that the pulmonary circulation escaped engorgement right up to the end. One might conclude that this was an example of Bernheim's syndrome in which a terminal "failure" of the right side of the heart occurred, without any indications of failure of the left ventricle. The presence of aortic stenosis would have led one to expect symptoms of left ventricular failure, but in this case again it would appear that engorgement upon the cavity of the right ventricle by the bulging septum precipitated the failure of the right side and protected the lungs.

Case 5. A clerk, aged 58, a tall, thin man, was sent to hospital with severe epistaxis. He was found to have a blood pressure of $220 / 130$, some enlargement of the left ventricle, the apex beat being of a powerful, thrusting character in the sixth intercostal space, four and a half inches from the midline. The peripheral arteries were thick, and the ischæmic, narrow retinal arterioles compressed the veins. There was a trace of albumin in the urine. There was no hepatic or jugular engorgement.

A month later he returned with œdema halfway up the shins, and distended jugular veins, whose fullness increased on compression of the abdomen. The heart rate was 80 , the beat regular. A gallop rhythm was audible and with this was associated a duplication of the apex beat, which was easily seen and felt. The aortic second sound was loud, but the pulmonary second sound was not. The cardiogram showed left axis deviation with a negative T I (Fig. 4). He had complained of no dyspnœa at all.

In connection with the last of these indications of embarrassment of the pulmonary circulation it was noted that there were no crepitations at the bases of the lungs, the skiagram (Fig. 8) showed no gross pulmonary engorgement.

After three weeks' treatment all signs of failure had cleared up and the gallop rhythm had disappeared. A few months later he died suddenly at home.

Comment. In this patient signs of congestive failure appeared in the systemic circulation, without the symptoms and pulmonary signs indicating prior failure of the left ventricle. The skiagram was clear; the circulation time (decholin) of only 28 seconds was but little prolonged.

For these reasons it seems correct to class this as an early case of Bernheim's syndrome. Although there was ready response to treatment at first, death occurred a few months later.

\section{TYPES OF LESION}

The underlying lesion in all these cases was either hypertension or aortic stenosis. These cause concentric hypertrophy of the left ventricle. Perusal of Bernheim's original series suggests that most of his patients were hypertensive, but no readings of the blood pressures were made. The same causes were present in Russell's series and those of Mazzei (1931), also in the series of 9 reported by Casaffourth and Superviola (1936). Aortic stenosis was present in Olmer's patient (1933) and in that described by Glushien and Geer (1943). For some reason the 


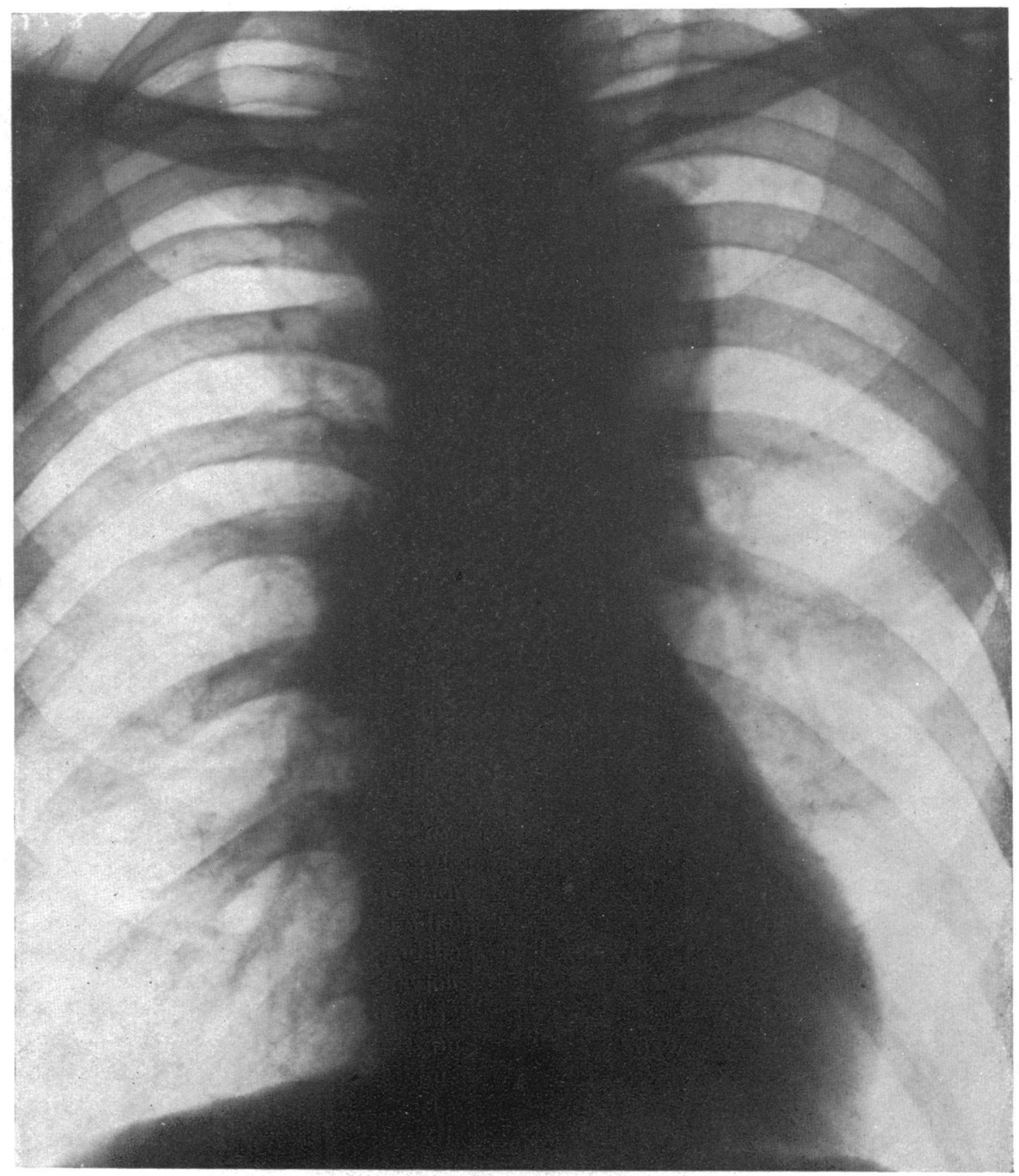

Fig. 8.-Case 5. No indication of pulmonary engorgement. Hypertrophy of left ventricle.

gross dilatation of the left ventricle caused by free aortic incompetence does not lead to right ventricular stenosis. Possibly the explanation is that the septum does not become sufficiently thick.

Appearances in the skiagram. It has been claimed that distension of the right auricle is a feature (Glushein and Geer, 1943). Two of our. cases suggested this, but in Case 5, admittedly in an early stage (Fig. 8), it is not present. The important point is the absence of engorgement of the fields of the lungs, although there may be slight overfilling of the pulmonary veins. We agree with other observers that the important triad is large left ventricle, clear lung fields, and full right auricle.

\section{Post-MORTEM FIndings}

The encroachment of the septum upon the cavity of the right ventricle is very obvious when the ventricles are cut across at right angles to the long axis of the heart, midway between the apex and the base. This finding is likely to be missed when the ventricles are opened by V-shaped cuts, one down the outer border and the other upwards to the pulmonary artery (or aorta), as is usually done. The transverse cut should really be made first of all in any post-mortem examination of the heart; this procedure might prevent the septal bulging from being overlooked, as we fancy it easily may be if the other procedure is followed. 
Photographs of the transversely divided ventricles are apt to be unsatisfactory, as by the time the heart has been opened the relative positions of the walls of the ventricles is lost: and plugging with cotton wool and fixing in formalin easily spoils the true shape. We attempted to make a cast, in two cases, of the upper part of the right ventricle and infundibulum. It is almost impossible to get a good photograph of this, but we were satisfied that this part, the outflow tract, remains tubular in form, leading up to the pulmonary artery, thus giving an outlet relieving the constriction below, as suggested by Russell and Zohman (1945) and earlier by Mazzei (1931).

\section{The Lungs}

The dryness of the lungs at autopsy, free from engorgement and œdema, as shown by their normal weight, is very striking. In all four cases this was a notable feature. This agrees, of course, with the relatively rapid circulation rate. Other observers have noted (e.g. Bernheim in five of his ten cases) infarcts in the lungs: whether these are due to emboli or thromboses is not clear.

Cooke and White (1941) point out that in tricuspid stenosis there is conspicuous jugular engorgement with freedom from pulmonary congestion, so that the patient may be able to lie flat and even walk about with but little distress. Constriction of the pericardial sac presents the same apparent paradox, as Glushien and Geer (1943) have noted. The syndrome of Bernheim, by reason of the right ventricular stenosis, presents a third example of this curious combination of signs; it amounts, in fact, as Fishberg has stated (1940), to "a virtual tricuspid stenosis."

\section{OTHER FINDINGS}

The circulation rate. In two of our patients (Cases 1 and 5) in which the observation was made the circulation rate was not grossly slowed, the arm to tongue time in both being 28 seconds. This is quite unlike the result one would expect in ordinary congestive failure, when it should be well over 40 seconds. Similar observations were made by Russell and Zohman (1945). As slowing chiefly occurs in the pulmonary circulation, the results indicate the relative freedom of the lungs from embarrassment.

The cardiogram. It will be noted that three of the curves in these cases of left ventricular hypertrophy show the expected left axis deviation in the three standard limb leads. In one this feature is absent and in another there is actually right axis deviation. There has been a good deal of comment on this absence of the curve of left axis deviation, and it has been suggested that the bulging of the septum of the ventricles to the right may be the cause of these curves by affecting the electrical axis (Russell, Zohman, 1945). It seems to us that the explanation is to be found in the unipolar limb leads, which show that the heart is actually vertically placed in the chest, and so the presence of the hypertrophy of the left ventricle cannot cause left axis deviation. This is not an uncommon finding in certain cases of left ventricular hypertrophy; quite apart from the presence of septal displacement to the right. We have recently noted three patients with aortic stenosis, two congenital in youths, and the third of the fibrocalcareous acquired type in an elderly man, who showed no left axis deviation, but with unipolar limb leads showing the heart to be vertical.

We therefore conclude that there are no cardiographic changes peculiar to Bernheim's syndrome.

Further investigation. It seems likely that two lines of investigation in such cases as these will be fruitful. It would be interesting to know what pressures may be revealed in the pulmonary artery by intracardiac catheterization. Angiocardiography should show the peculiar shape of the cavity of the right ventricle.

\section{TREATMENT}

In these cases the question of venesection may arise. It would seem inadvisable to bleed in these circumstances, as a raised venous pressure is no doubt beneficial. Anything that reduces the venous pressure might do harm; and this perhaps applies to such drugs as digitalis and cardophylin.

\section{SUMMARY}

Right ventricular stenosis (Bernheim's syndrome) may be found in patients with hypertension or aortic stenosis.

The symptoms suggesting failure of the right ventricle come on early, and may be transient at first. The pulmonary circulation remains free from embarrassment, and the patient is free from orthopnœa, even to the end.

The clinical diagnosis is confirmed at autopsy by the state of the lungs and transverse section of the ventricles.

There are no cardiographic changes peculiar to the condition.

Our thanks are due to Professor Magnus for Fig. 5, and Dr. J. V. Wilson for Fig. 7. 


\section{REFERENCES}

Casaffourth, C. F. S., and Suberviola, J. (1936). Prensa Mazzei, E. S. (1931). Rev. de Méd., 48, 493. méd. Arg., 23, 193.

Cooke, W. T., and White, P. D. (1941). Brit. Heart J., 3,147 .

Olmer, J., Buisson Paillas, J., and Bernard, R. (1933). Marseille-méd., 2, 615.

Fishberg, A. M. (1940). . Heart Failure. Philadelphia, Lee and Febiger.

Podestà, F. E. (1936). Cuore e Circolaz., 20, 290.

Russell, H. I., and Zohman, B. L. (1945). Amer. Heart J., 30, 427.

Glushien, A. S., and Geer, J. A. (1943-44). Med. Bull. Vet. Admin., 20, 277. 